\title{
Maternal mortality audit in Suriname between 2010 and 2014, a reproductive age mortality survey
}

Lachmi R. Kodan ${ }^{1 * \dagger}$, Kim J. C. Verschueren ${ }^{2 \dagger}$, Jos van Roosmalen ${ }^{3,4}$, Humphrey H. H. Kanhai ${ }^{4,5}$ and Kitty W. M. Bloemenkamp²

\begin{abstract}
Background: The fifth Millennium Development Goal (MDG-5) aimed to improve maternal health, targeting a maternal mortality ratio (MMR) reduction of 75\% between 1990 and 2015. The objective of this study was to identify all maternal deaths in Suriname, determine the extent of underreporting, estimate the reduction, audit the maternal deaths and assess underlying causes and substandard care factors.

Methods: A reproductive age mortality survey was conducted in Suriname (South-American upper-middle income country) between 2010 and 2014 to identify all maternal deaths in the country. MMR was compared to vital statistics and a previous confidential enquiry from 1991 to 1993 with a MMR 226. A maternal mortality committee audited the maternal deaths and identified underlying causes and substandard care factors.

Results: In the study period 65 maternal deaths were identified in 50,051 live births, indicating a MMR of 130 per 100. 000 live births and implicating a $42 \%$ reduction of maternal deaths in the past 25 years. Vital registration indicated a MMR of 96 , which marks underreporting of $26 \%$. Maternal deaths mostly occurred in the urban hospitals (84\%) and the causes were classified as direct (63\%), indirect (32\%) or unspecified (5\%). Major underlying causes were obstetric and non-obstetric sepsis (27\%) and haemorrhage (20\%). Substandard care factors (95\%) were mostly health professional related (80\%) due to delay in diagnosis (59\%), delay or wrong treatment (78\%) or inadequate monitoring (59\%). Substandard care factors most likely led to death in $47 \%$ of the cases.

Conclusion: Despite the reduction in maternal mortality, Suriname did not reach MDG-5 in 2015. Steps to reach the Sustainable Development Goal in 2030 (MMR $\leq 70$ per 100.000 live births) and eliminate preventable deaths include improving data surveillance, installing a maternal death review committee, and implementing national guidelines for prevention and management of major complications of pregnancy, childbirth and puerperium.
\end{abstract}

Keywords: Maternal mortality, Middle-income country, Mmr, Suriname, RAMoS, Underreporting

\section{Background}

Reducing maternal mortality is one of the major challenges to health systems worldwide. United Nations' Millennium Development Goal 5 (MDG-5) called for a $75 \%$ reduction of the maternal mortality ratio (MMR) between 1990 and 2015. The global MMR fell from 385 deaths per 100.000 live births in 1990 to 216 in 2015,

\footnotetext{
* Correspondence: lachmikodan@yahoo.com

${ }^{\dagger}$ Equal contributors

${ }^{1}$ Department of Obstetrics, Academic Hospital Paramaribo (AZP), Paramaribo, Suriname

Full list of author information is available at the end of the article
}

corresponding to a decline of $44 \%$. A vision of ending all preventable maternal deaths has emerged in 2015, being one of the Sustainable Development Goals (SDGs); it aims to reduce the global MMR to less than 70 deaths per 100.000 live births by 2030 . Achievement of this target will require robust information systems with highquality data, specifically on causes of death, as it is of great importance in informing decision-makers and ultimately reducing maternal mortality [1].

UN's Maternal Mortality Estimation Inter-Agency Group reports that Suriname is one of the few countries with an increase in MMR from 127 in 1990 to 155 in 
2015 [2, 3]. However, a confidential enquiry by Mungra et al. reported a MMR of 226 per 100.000 live births in 1991-1993, suggesting a $31 \%$ decrease instead of the $25 \%$ increase as suggested by the UN $[4,5]$. However, it is unclear whether, and if so, to what extent, vital registration has become more reliable over the years.

Maternal health outcomes are strongly associated with higher capital levels, suggesting that an increase in Gross National Income (GNI) per capita should correspond with a reduction in maternal mortality [6]. Suriname was upgraded from lower-middle income country to upper-middle income country in 2013 as the GNI increased from $\$ 1430$ in 1990 to $\$ 9370$ in 2013 [7]. Yet, progress made on different basic health indicators (e.g. under five mortality, health insurance coverage and maternal mortality) in the country is relatively marginal [8].

According to WHO-estimates, Suriname (MMR 155) belongs to the four worst performing countries in Latin America and the Caribbean (Haiti - MMR 359, Guyana MMR 229 and Bolivia - MMR 206) [1-3]. These are, in contrast to Suriname, low and lower-middle income countries. Suriname's poor performance concerning maternal mortality is unexplained, as the country performs fairly well on maternal health indicators, e.g. skilled professionals attended $96 \%$ of the deliveries in the coastal area and $77 \%$ in the rural interior and antenatal care visits occurred at least once in $91 \%$ of the pregnant women and at least four times in 67\% [8].

Therefore, the aim of the study is first to identify all maternal deaths in Suriname from 2010 to 2014, second to determine whether maternal deaths were accurately registered and classified, third to assess the reduction of maternal deaths in 25 years, fourth to perform an indepth audit of the deaths and finally to determine the level of substandard care.

\section{Methods}

\section{Study design}

A reproductive age mortality survey (RAMoS) was conducted, using different methods to identify maternal deaths nationwide in Suriname between January 1st 2010 and December 31st 2014.

\section{Study setting}

Suriname is a multi-ethnical South American country with a population of 541,638 served by four referral hospitals in the capital, Paramaribo, and one hospital near the western coast, Nickerie. In addition to general practitioners, Regional Health Services (RGD) and Medical Mission (MZ) are responsible for primary healthcare. RGD comprises of 43 facilities serving the whole coastal area and the Medical Mission has 56 health posts throughout the interior. Figure 1 demonstrates the urban area I (Paramaribo) and II (Nickerie), rural coastal area III and rural interior IV. Annually approximately 10,000 live births take place, of which hospitals cover an estimated $82 \%$ and primary health institutions $10 \%, 4 \%$ of deliveries are at home and the remaining $4 \%$ is unknown [9]. Social insurance, which is for the near poor and poor population, covers an estimated $45 \%$ ofthe general population. The ethnic distribution among the female population is Hindustani (28\%), Maroon (24\%), Creole (18\%), Javanese (14\%), Mixed (14\%) and other (2\%) [10].

\section{Classification \& definitions}

According to the ICD-MM a pregnancy-related death is the death of a woman while pregnant or within 42 days of termination of pregnancy, irrespective of the cause [11]. A maternal death is the death of a woman while pregnant or within 42 days of termination of pregnancy, irrespective of the duration and site of the pregnancy, from any cause related to or aggravated by the pregnancy or its management but not from accidental or incidental causes. Direct obstetric deaths are those resulting from obstetric complications, while indirect obstetric deaths are those resulting from either a previous existing disease or a disease that developed during pregnancy and which is not due to direct obstetric causes, but which is aggravated by physiologic effects of pregnancy. In unspecified maternal deaths the underlying cause is unknown or cannot be determined. Late maternal deaths are direct or indirect deaths, more than 42 days, but less than 1 year after termination of pregnancy. MMR is the number of direct, indirect and unspecified maternal deaths per 100,000 live births [11, 12].

\section{Data collection}

Vital registration Maternal deaths in Suriname are identified mainly by the collection of death certificates and sporadic informing in the hospitals. No independent surveillance systems are adapted to investigate deaths in women of reproductive age. Notification of death is compulsory by law. However burial can take place without the official death certificate, when there is 'an act of death' (an unofficial note signed by a medical doctor). The death certificate is filled in afterwards and often received with a delay ( $>3$ months) and in 15\% not received at all. In addition the death certificate lacks a pregnancy checkbox [13]. Identified maternal deaths are not reviewed and thus not classified. Due to a lack of classification, most accidental/incidental deaths and late maternal deaths are also included in the official maternal mortality statistics.

Reproductive age mortality survey (RAMoS) The RAMoS consisted of different steps. First, case records of maternal deaths from 2010 to 2014 identified by vital registration were collected. Second, all medical records of 


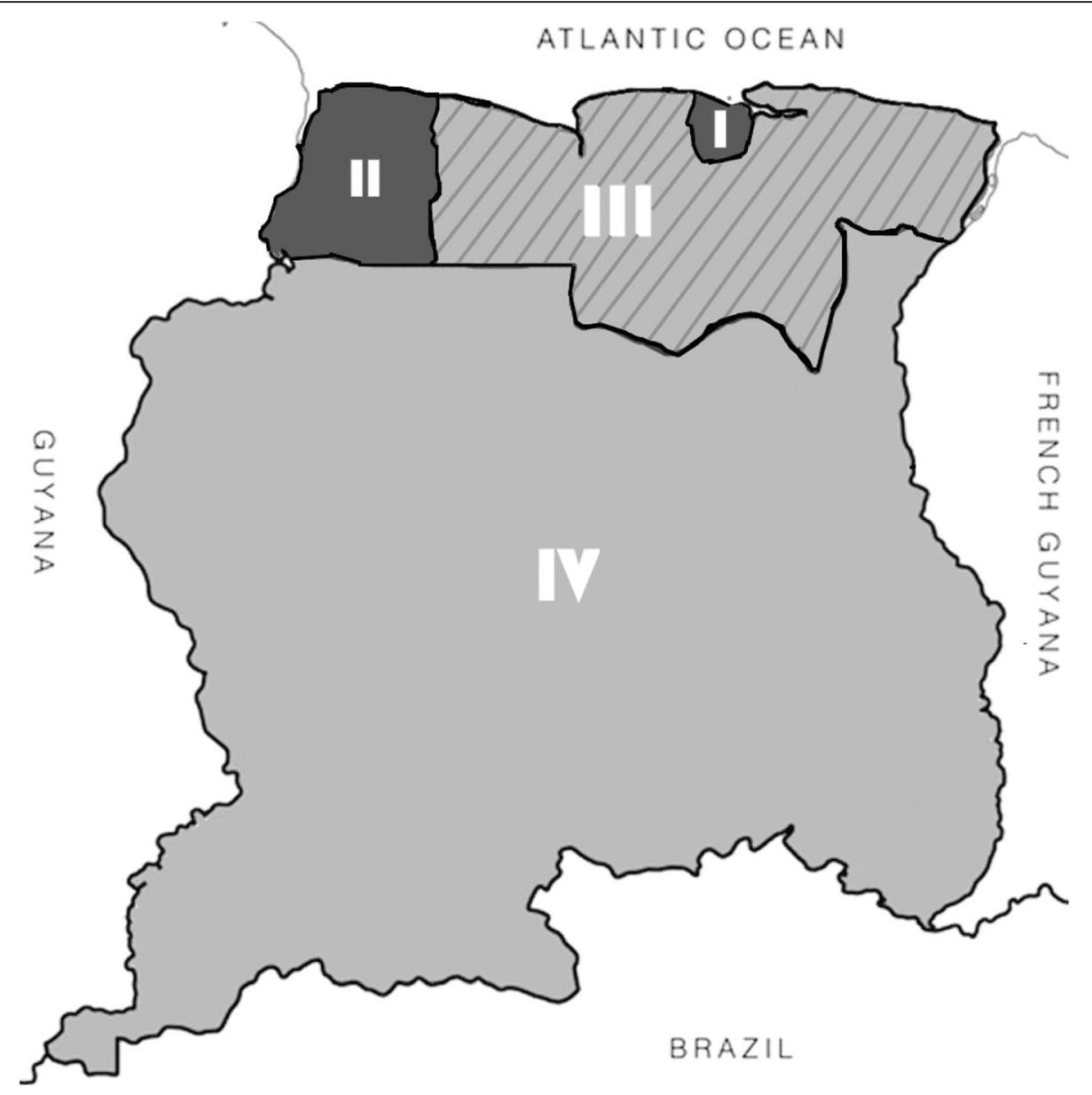

Fig. 1 Map of Suriname divided in the urban (I-II), rural coastal (III) and rural interior (IV)

deceased women aged 10 to 50 years in our study period were collected from the archives of all hospitals and the primary health care institutions (Medical Mission and Regional Health Services). Third, The Central Bureau of Civil Affairs provided a list of all deceased women in the country between 2010 and 2014 with an offspring in the preceding year. Fourth, an inventory was performed in the largest mortuary (receiving also deaths occurring outside health care institutions). Fifth, obstetric health care professionals in all facilities were asked their knowledge on local maternal deaths in the past 5 years.

Medical records were collected and examined extensively and in case of an incomplete file involved health care professionals were interviewed. Verbal autopsy with family member(s) was performed when maternal deaths occurred outside of the hospital. This was conducted according to the WHO-instrument on verbal autopsy [14]. All available information was gathered (i.e. laboratory and pathology reports, in delivery-books and autopsy information).

An elaborate clinical case summary of every pregnancyrelated death was made according to the FIGO-LOGIC MDR: Clinical summary form tool [15]. Information on patients, health care providers and hospitals was kept strictly confidential.

An expert committee, consisting of different obstetricians, an internal medicine specialist or anaesthesiologist and midwives, audited all pregnancy-related deaths with two authors (LK and KV) presenting and moderating the sessions. When no consensus was achieved, external expert opinion (JR and HK) was sought. The committee reviewed the cases and agreed to a mode of death, underlying cause, contributing factors and classified each death using WHO guidelines on applications of ICD-MM [12]. Substandard care factors were analysed according to an adapted version of the FIGO-LOGIC MDR Grid analysis of clinical case management form [15]. Due to lack of guidelines substandard care was defined as a deviation from 'standard practice' according to local clinicians.

\section{Data analysis}

Data were manually entered into IBM SPSS version 21.0 (Armonk, New York, USA) for analysis. All maternal deaths were individually analysed and cross-linked with registered maternal deaths by civil registration. Causes, 
contributing factors and substandard care factors were recoded into categorical variables.

\section{Results}

Of the 1335 deceased women of reproductive age between 2010 and 2014, 71 were pregnancy-related and 65 were maternal deaths (Fig. 2). The 65 maternal deaths were identified among 50.051 live births, resulting in a MMR of 130 with an annual range from 69 to 154 per 100.000 live births (Table 1).

\section{Underreporting}

Underreporting occurred by misidentification in $26 \%$ $(n=17)$ and by misclassification in $65 \%(n=31)$ (Table 1 ). The predictive value for the current vital registration to identify maternal deaths is $74 \%(48 / 48+17)$.

The maternal deaths not identified by vital registration $(n=17)$ occurred in the hospitals in $88 \%(n=15)$ or at home in $12 \%(n=2)$. The causes of these hospitaldeaths were infectious diseases in $87 \%(n=13)$, admitted and deceased on non-obstetric wards. These death certificates did not indicate or suggest that the woman was or had been pregnant. Maternal deaths, which were identified by vital registration but were classified incorrectly, consisted of deaths without the cause mentioned on the death certificate $(n=9)$, non-obstetric diseases ( $n=13)$, deaths complicated with more than one diagnosis $(n=8)$ and cases in which the mode of death was reported on the death certificate rather than the underlying cause $(n=17)$.

Apart from the 48 true maternal deaths identified by vital registration, another 5 maternal deaths were incorrectly classified as maternal deaths (these were accidental or incidental causes or late maternal deaths).

\section{Characteristics of maternal deaths}

The women in Suriname who died during pregnancy, childbirth or puerperium lived in a rural coastal area or in the rural interior in respectively 15 and 17\% (Fig. 1 and Table 2). Maternal deaths, however, occurred in these areas in respectively 5 and 6\%. Maternal deaths in urban hospitals $(84 \%)$ occurred on the ICU (60\%), ward $(30 \%)$ or emergency or operating room $(10 \%)$. Characteristics of maternal deaths are shown in Table 3.

Social insurance, indicating the (near) poor, covered $69 \%(n=45)$ of the deceased women. Socially insured women were maroons or creoles in $75 \%(n=34)$ of the cases. Anaemia $(\mathrm{Hb} \leq 6.0 \mathrm{mmol} / \mathrm{L})$ complicated $45 \%$ of the cases. Post-mortem investigation was performed in $3 \%(n=2)$ of maternal deaths.

\section{Classification and causes of maternal deaths}

Of the 65 maternal deaths, 41 (63\%) were due to direct causes, $21(32 \%)$ due to indirect causes and three (5\%)

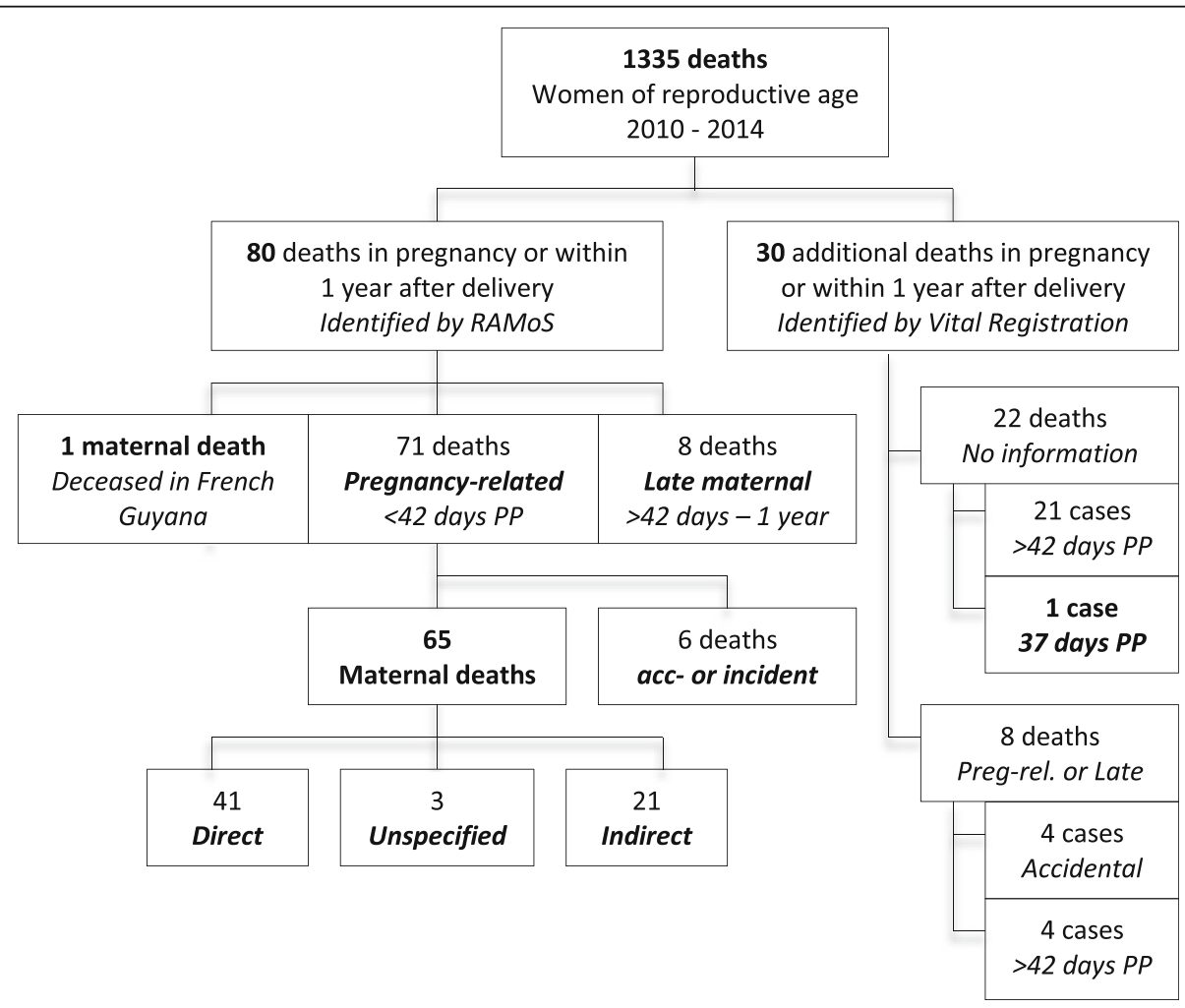

Fig. 2 Flowchart of pregnancy related deaths in Suriname (RAMoS and vital registration) 
Table 1 MMR and number of maternal deaths found by RAMOS in comparison to vital registration

\begin{tabular}{lllllll}
\hline & 2010 & 2011 & 2012 & 2013 & 2014 & Total \\
\hline $\begin{array}{l}\text { Live births } \\
\text { RAMoS }\end{array}$ & 9712 & 9703 & 10,217 & 10,012 & 10,407 & 50,051 \\
$\quad$ MMR & 154 & 144 & 69 & 130 & 154 & 130 \\
$\quad \begin{array}{l}\text { Maternal deaths } \\
\text { Vital registration }\end{array}$ & 15 & 14 & 7 & 13 & 16 & 65 \\
$\quad$ MMR & 82 & 103 & 49 & 120 & 125 & 96 \\
$\quad \begin{array}{l}\text { Maternal deaths } \\
\text { Underreporting }\end{array}$ & 8 & 10 & 5 & 12 & 13 & 48 \\
$\quad$ Misclassification of & 50 & 60 & 60 & 75 & 70 & 65 \\
$\begin{array}{l}\text { causes (\%) } \\
\quad \text { Misidentification (\%) }\end{array}$ & 47 & 28 & 30 & 8 & 18 & 26 \\
$\quad$ Correction factor & 1.88 & 1.40 & 1.40 & 1.08 & 1.23 & 1.35 \\
\hline
\end{tabular}

maternal deaths were classified as unspecified because the cause of death was unknown (Fig. 3). The two leading causes of maternal mortality were obstetric and nonobstetric sepsis $(n=18,27 \%)$ and obstetric haemorrhage $(n=13,20 \%)$.

Obstetric haemorrhage was mainly due to postpartum haemorrhage $(n=11,85 \%)$ caused by uterine atony (29\%), retained placenta (23\%), ruptured uterus (15\%), vaginal / cervical tear (8\%), and unspecified causes (10\%). Underlying cause of all ante partum haemorrhages was placental abruption $(n=2,15 \%)$.

Hypertensive disorders and its complications (e.g. cerebral bleeding, HELLP, eclampsia) accounted for $14 \%$ of maternal deaths. However, hypertensive disorders, such as pregnancy induced hypertension and preeclampsia, were diagnosed in $30 \%$ of all maternal deaths.
Though not the underlying cause of death, they were commonly classified as a contributing factor.

The remaining other causes of direct maternal deaths ( $n=8,12 \%)$ were four probable amniotic fluid embolisms, one obstructed labour, one suicide by intoxication at 24 weeks, one case of acute fatty liver of pregnancy with consequently hepatic encephalopathy and multiorgan failure. The underlying cause of one case remained unknown as the woman died without any reported symptoms within a few hours after caesarean section for foetal indication.

Sepsis occurred either due to direct obstetric complications (9\%) of which one third had puerperal sepsis while being HIV positive or due to medical conditions aggravated by the pregnancy (e.g. non-obstetric septicaemia, pneumonia, gastro-enteritis, AIDS) and therefore were classified as indirect maternal deaths (18\%).

The other non-sepsis indirect maternal deaths $(n=9)$ concerned two cases of endocarditis resulting in heart failure, one pulmonary bleeding caused by idiopathic thrombocytopenia, one case of end-stage renal failure due to diabetes and one woman, diagnosed with preexistent hypertension, died due to a cerebrovascular accident.

Substandard care factors were found in 95\% ( $n=56 /$ 59) of the cases (Table 4). More than 5 substandard care factors were present in $55 \%$ of cases.

In $80 \%$ of the cases care provided by health professionals was below the standard due to delay in diagnosis (59\%), inadequate treatment $(78 \%)$ or poor monitoring (59\%). Blood transfusion was unavailable in 10 of 31 cases (32\%) when this was required. An ICU bed was not available when requested in 11 (24\%) of 45 cases. The committee agreed that in $47 \%$ of the maternal

Table 2 Demographics of Surinamese population in relation to maternal deaths

\begin{tabular}{|c|c|c|c|c|}
\hline & Area I & Area II & Area III & Area IV \\
\hline & $\begin{array}{l}\text { Urban } \\
\text { Paramaribo Wanica }\end{array}$ & $\begin{array}{l}\text { Urban } \\
\text { Nickerie }\end{array}$ & $\begin{array}{l}\text { Rural coastal } \\
\text { Coronie, Saramacca, Para, } \\
\text { Commewijne, Marowijne }\end{array}$ & $\begin{array}{l}\text { Rural interior } \\
\text { Brokopondo } \\
\text { Sipaliwini }\end{array}$ \\
\hline General population, $n=534.189$ & $66 \%$ & $6 \%$ & $18 \%$ & $10 \%$ \\
\hline \multicolumn{5}{|l|}{ Live births (2010-2014), $n=50.051$} \\
\hline Residency & $67 \%$ & $4 \%$ & $18 \%$ & $11 \%$ \\
\hline Location of delivery ${ }^{a}$ & $77 \%$ & $5 \%$ & $5 \%$ & $5 \%$ \\
\hline \multicolumn{5}{|l|}{ Maternal deaths, $n=65(\%)$} \\
\hline Location of residence & $40(62)$ & $4(6)$ & $10(15)$ & 17 \\
\hline \multicolumn{5}{|l|}{ Location of death } \\
\hline Hospital, $n=55$ (84) & $53(81)$ & $2(3)$ & N/A & $\mathrm{N} / \mathrm{A}$ \\
\hline Primary health care, $n=5$ (8) & - & - & $3(5)$ & $2(3)$ \\
\hline Home, $n=5$ (8) & $3(5)$ & - & & $2(3)$ \\
\hline MMR per 100.000 live births & 145 & 80 & 120 & 160 \\
\hline
\end{tabular}

anknown location of live births in $8 \%$ (of which $50 \%$ of live births at home) 
Table 3 Socio-demographic and obstetrical characteristics of all maternal deaths

\begin{tabular}{|c|c|}
\hline & $n=65(\%)$ \\
\hline \multicolumn{2}{|l|}{ Age } \\
\hline$<20$ & $11(17)$ \\
\hline $20-35$ & $42(64)$ \\
\hline $36-50$ & $12(18)$ \\
\hline Mean, range of age & $29,16-45$ \\
\hline \multicolumn{2}{|l|}{ Ethnicity } \\
\hline Hindu & $12(18)$ \\
\hline Creole & $13(20)$ \\
\hline Maroon & $24(37)$ \\
\hline Javanese & $8(12)$ \\
\hline Indigenous (Amerindians) & $3(5)$ \\
\hline Mixed & $5(8)$ \\
\hline \multicolumn{2}{|l|}{ Insurance $(n=63)$} \\
\hline Social insurance (poor) & $45(69)$ \\
\hline State Health & $10(15)$ \\
\hline Private & $8(12)$ \\
\hline \multicolumn{2}{|l|}{ Antenatal care $(n=58)$} \\
\hline None & $12(23)$ \\
\hline$<4$ & $8(15)$ \\
\hline$\geq 4$ & $33(62)$ \\
\hline \multicolumn{2}{|l|}{ Parity at time of death $(n=62)$} \\
\hline 0 & $5(8)$ \\
\hline 1 & $14(23)$ \\
\hline 2 & $17(27)$ \\
\hline$\geq 3$ & $26(42)$ \\
\hline \multicolumn{2}{|l|}{ Pregnancy state } \\
\hline $\mathrm{GA}<16$ weeks & $5(8)$ \\
\hline Antepartum & $15(23)$ \\
\hline GA $16-27$ weeks & $4(6)$ \\
\hline $\mathrm{GA}>28$ weeks & $9(11)$ \\
\hline Durante partum (GA > 37) & $4(6)$ \\
\hline Post-partum & $41(63)$ \\
\hline \multicolumn{2}{|l|}{ Mode of delivery $(n=41)$} \\
\hline Spontaneous, vaginal & $25(61)$ \\
\hline Ventouse & $3(7)$ \\
\hline Caesarean-section & $13(32)$ \\
\hline \multicolumn{2}{|l|}{ Perinatal death $(n=57)$} \\
\hline Yes & $36(64)$ \\
\hline Intrauterine fetal death & $8(14)$ \\
\hline Post-partum (<7 days) & $8(14)$ \\
\hline
\end{tabular}

deaths substandard care factors certainly $(21 \%)$ or most likely (26\%) led to death.

\section{Discussion}

The MMR in Suriname is 130 per 100,000 live births between 2010 and 2014. Mungra et al. reported a MMR of 226 between 1991 and 1993, which indicates a $42 \%$ reduction in maternal deaths and an improvement in underreporting from $64 \%$ to $26 \%[4,5]$. A comparison of the MMR and underreporting is difficult, as to our best knowledge there are few countries that have performed a RAMoS of confidential enquiry [16-19].

\section{Underreporting}

Though our study suggests that, over the years, there is a growing reliability on identification of maternal deaths, the underreporting rate in Suriname (26\%) is still higher than reported in Jamaica (20\%), Argentina (9.5\%) and Mexico (13\%) [16-19].

The underreporting due to misidentification of maternal deaths in Suriname can be explained by numerous facts: first, physicians are not obliged to report maternal deaths. Second, part of the death certificate (including the cause of death) is not always available as it is not obliged to be completed before the burial takes place. Third, the death certificate does not include a pregnancy checkbox and finally no active enquiry or RAMoS is performed. The effectiveness of a pregnancy check box on death certificates has proven to be effective in identifying pregnancy-associated mortality [20, 21]. Misclassification of deaths by vital registration in Suriname can be explained by different factors. First, maternal death causes are designated by the ICD-code on the death certificate (patient records frequently unavailable), while the ICDMM coding alone is considered inadequate [22]. Second, post-mortem investigations are rare. Third, verbal autopsies and maternal death reviews are not performed to identify causes. These last strategies are best in identifying causes and evaluating quality of care in order to improve $[11,14,15,22]$.

\section{Characteristics \& causes}

Social insurance as a marker indicating poverty was found in the majority of maternal deaths (69\%), while less than half of the general population had social insurance. A difference in ethnicity is seen between the general female population (Hindustani 28\%; Maroon 24\%; Mixed 14\%) and the maternal deaths (Hindustani 18\%; Maroon 37\%; Mixed 8\%). Similar to two decades ago, obstetric haemorrhage is the most common direct cause of death, which is lower than reported in low-income countries (27\%) and higher than in high-income countries (16\%) [3]. Hypertensive disorders are known to be an important cause of maternal deaths in Latin America 


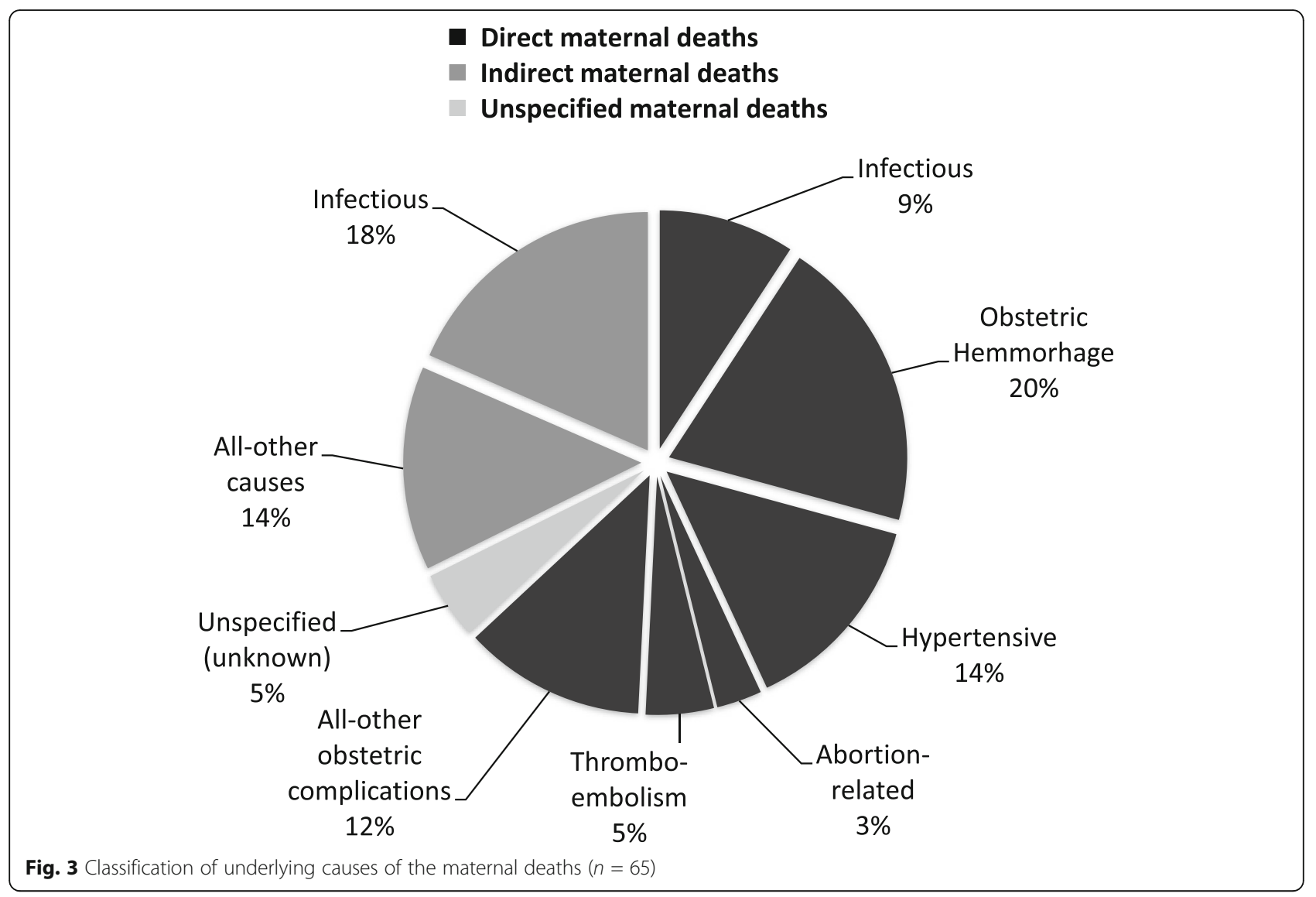

Table 4 Substandard care factors analysed in 59 of the 65 cases of maternal deaths

\begin{tabular}{ll}
\hline & $n=59(\%)$ \\
\hline Professional factors & $47(80)$ \\
Quality & $11(19)$ \\
Availability & $13(22)$ \\
Attitude / work-ethic & \\
Medical service factors & $35(59)$ \\
Wrong or delay in diagnosis & $46(78)$ \\
No/inadequate treatment & $35(59)$ \\
Poor monitoring & $19(32)$ \\
Communication & \\
Unavailability & $8(14)$ \\
Diagnostics (eg. lab, pathology) & $11(24)$ \\
ICU-bed ( $n=45)$ & $10(32)$ \\
Blood $\left(n=31^{*}\right)$ & $12(20)$ \\
Supplies / medication & \\
Patient factors & $13(22)$ \\
Poor compliance to treatment & $4(7)$ \\
Refusing treatment & $9(15)$ \\
Delay in transportation &
\end{tabular}

and the Caribbean (22\%) [1-3]. While eclampsia was the underlying cause in just $14 \%$ of the deaths in Suriname, it was an important contributing factor $(30 \%)$ to deaths with another underlying cause. The authors advise health authorities to implement nationwide protocols for the prevention and management of hypertensive disorders and post-partum haemorrhage. Illegal abortion is the cause of death in only one case $(1.5 \%)$, which is in great contrast to the $12 \%$ abortion-related deaths in Latin America and the Caribbean [3, 17, 19]. Although illegal in Suriname, most abortions are self-induced with misoprostol and women present with an incomplete abortion after which safe surgical evacuation is performed in the hospital by a gynaecologist or gynaecologist in training. However, since termination of pregnancy is not registered, underreporting could have occurred.

Indirect maternal deaths (32\%), in particular nonobstetric sepsis (18\%), accounted for a greater part of the maternal deaths in our study compared to the 27\% of other Latin American and Caribbean countries [3]. Therefore, we recommend that these maternal deaths from should be analysed in detail to gain more knowledge of underlying causes, circumstances and preventive measurements. 


\section{Why do pregnant women die in Suriname and what can we do about it?}

The most striking finding of our survey is that the majority of maternal deaths occurred in hospital (85\%) with the most important substandard care factor being delay in diagnosis (59\%) and delay in treatment by health care providers, and less frequently due to patient delay (15\%). This finding necessitates actions such as training and retaining skilled staff and implementation of evidencebased guidelines. Another important finding is that most of the deaths occurred postpartum, indicating that improvements can be made in the care provided in the period after birth. Patients should be provided with more information. We advise more frequent and qualitative better postnatal checks and if necessary home-visits should be performed. Lastly, a great number of maternal deaths occurred on the wards (30\%) and the monitoring of patients is found to be inadequate in 59\% of these cases. Implementation of an early warning system for timely interventions in order to reduce serious adverse events has been proven effective and is recommended [23].

Limitations of this study are indwelled in its retrospective nature. Though we performed a robust enquiry, maternal deaths could have been missed, especially if they occurred outside of health care facilities or during early pregnancy. In addition, not all case files were available, records were often incomplete and post-mortem investigations were generally not performed. This affected the quality of the classification of causes and evaluation of substandard care during the maternal death reviews. Finally, but most importantly, due to lack of national data on characteristics of the pregnant population, pregnancy and delivery, we were not able to perform multivariate analysis and assess risk factors.

\section{Conclusion}

Suriname has a high MMR compared to other Latin American countries and the Caribbean with similar or lower income economies. We highly recommend (1) to improve national data surveillance, (2) install a maternal mortality committee to review all maternal deaths, (3) implement an early warning score and national guidelines on postpartum haemorrhage and eclampsia and (4) improve postnatal care strategies. Lastly, as maternal mortality is merely the tip of the iceberg, severe morbidity research should be conducted to assess and prevent severe obstetric complications and make progress to reach the SDG of a MMR $<70$ in 2030.

\section{Abbreviations}

BOG: Bureau of public health (Bureau Openbare Gezondheidszorg); FIGO-

LOGIC: International federation of gynaecology and obstetrics - leaderschip in obstetrics and gynaecology for impact \& change; GNI: Gross national income; ICD-MM: International statistical classification of diseases - maternal mortality; ICU: Intensive care unit; MDG: Millennium development goals; MDR: Maternal death review; MMR: Maternal mortality ratio; MZ: Medical Mission (Medische Zending); RAMoS: Reproductive age mortality survey; RGD: Regional health services (Regionale Gezondheidsdienst);

SDG: Sustainable development goals

\section{Acknowledgements}

The authors wish to thank the Ministry of Health of Suriname, the Bureau of Public Health and the Central Bureau of Civil Registration for their support, as well as the hospital boards of all hospitals, Regional Health Services and Medical Mission for making this study possible. V. Jairam and other employees of the archives and students are acknowledged for helping collect the data. The authors would like to thank the obstetricians (G. Essed, P. Goerdin, R. Charles, R. Tjon Kon Fat, H. Karansingh, R. Tjon A Fat, L. Olmtak, M. Sietaram, O.

Ramkhelawan, K. Ramkhelawan, S. Mohan, M. Dipoikromo), gynaecology residents (F. Rigters and S. Cornelisse), internal medicine specialists (K. Waldring, S. Vreden, A. Niekoop, J. Adhin, P. Issa and A. Punwasi), anaesthesiologists (M. Tjon Sie Fat, D. Nahar), neurologist (S. de Jong) and midwives (M. Fitz Jim, S. Abente, S. Holband, A. Naarden, J. Kloppenburg) for their valuable participation in the analysis of the cases. J. Brown (MD) and B. Jacod (MD, PhD) are acknowledged for their guidance in the analysis and advisory role in the first stages of the writing process.

\section{Funding}

The study was not funded.

\section{Availability of data and materials}

The data analysed during this study are included in this published article. Additional data used and/or analysed during the current study are available from the corresponding author on request.

\section{Authors' contributions}

LK and KV both conceived the study and contributed equally to the methodology, the execution and first and final versions of the manuscript. While LK coordinated all the logistics and closely supervised constantly, KV was more involved with case collection, case summaries and performing the statistical analysis. JR and HK contributed to case analyses and writing of the paper. KB was involved in revising analysis, advising the principal investigators and revising the manuscript. All authors have approved the final manuscript.

\section{Ethics approval and consent to participate}

The research has been performed in accordance with the Declaration of Helsinki and has been approved by the medical ethical review board of the Surinamese Central Committee on Research Involving Human Subjects [Reference number: VG 006-15] on March 9th, 2015.

\section{Consent for publication}

The manuscript contains individual deceased person's data in an aggregated form. Consent was obtained from the Ministry of Health and personal consent was not applicable.

\section{Competing interests}

The authors declare that they have no competing interests.

\section{Publisher's Note}

Springer Nature remains neutral with regard to jurisdictional claims in published maps and institutional affiliations.

\section{Author details}

${ }^{1}$ Department of Obstetrics, Academic Hospital Paramaribo (AZP), Paramaribo, Suriname. ${ }^{2}$ Department of Obstetrics, Birth Centre Wilhelmina's Children Hospital, University Medical Centre Utrecht, Utrecht, the Netherlands.

${ }^{3}$ Athena Institute, VU University Amsterdam, Amsterdam, the Netherlands. ${ }^{4}$ Department of Obstetrics, Leiden University Medical Centre, Leiden, the Netherlands. ${ }^{5}$ Anton de Kom University, Paramaribo, Suriname.

Received: 29 April 2016 Accepted: 22 August 2017

Published online: 29 August 2017

References

1. GBD 2015 Maternal Mortality Collaborators. Global, regional, and national levels of maternal mortality, 1990-2015: a systematic analysis for the global 
burden of disease study 2015. Lancet. 2016;388(10053):1775-812. doi:10. 1016/S0140-6736(16)31470-2.

2. Alkema L, Chou D, Hogan D, Zhang S, Moller A, Gemmill A, et al. Global, regional, and national levels and trends in maternal mortality between 1990 and 2015, with scenario-based projections to 2030: a systematic analysis by the UN maternal mortality estimation inter-agency group. Lancet. 2016; 387(10017):462-74

3. Say L, Chou D, Gemmill A, Tuncalp Ö, Moller A, Daniels J, et al. Global causes of maternal death: a WHO systematic analysis. Lancet Glob Health. 2014:2(6):e323-33.

4. Mungra A, van Kanten R, Kanhai H, van Roosmalen J. Nationwide maternal mortality in Surinam. BJOG. 1999;106(1):55-9.

5. Mungra A, van Bokhoven S, Florie J, van Kanten R, van Roosmalen J, Kanhai $H$. Reproductive age mortality survey to study under-reporting of maternal mortality in Surinam. Eur J Obstet Gynaecol Reprod Biol. 1998;77(1):37-9.

6. Amiri A, Gerdtham U. Impact of Maternal and Child Health on Economic Growth: New Evidence Based Granger Causality and DEA Analysis. Newborn and Child Health, Study Commissioned by the Partnership for Maternal, Lund University, Sweden. 2013; 1-30. http:// www.who.int/pmnch/topics/part_publications/201303_Econ_benefits_ econometric_study.pdf Accessed 15 May 2015.

7. World Bank. 2015. World Development Indicators 2015. Country: Suriname. http://data.worldbank.org/country/suriname. Accessed April 2, 2015.

8. Ministry of Foreign Affairs, Suriname. Central Bureau of Statistics (ABS). Suriname MDG Progress Report 2014. UNDP. 2014. http://statistics-suriname org/index.php/statistieken/downloads/category/35-millenium-developmentgoals\%3Fdownload\%3D136:mdgs-2014+MDG+suriname+progress+report. Accessed 15 May 2015.

9. Government of Suriname and United Nations Children's Fund. Suriname Multiple Indicator Cluster Survey 2010. Final report. 2013. https://micssurveys-prod.s3.amazonaws.com/MICS2/ Latin\%20America\%20and\%20Caribbean/Suriname/1999-2000/Final/ Suriname\%201999-00\%20MICS_English.pdf. Accessed 15 May 2015.

10. General Bureau of Statistics - Suriname. Statistical Yearbook 2013. Suriname in numbers no. 310-2014/11. 2014. Accessed 15 May 2015.

11. The WHO Application of ICD-10 to Deaths During Pregnancy, Childbirth and the Puerperium: ICD-MM. World Health Organization, Geneva. 2013. Accessed 10 Apr 2015

12. Beyond the numbers: reviewing maternal deaths and complications to make pregnancy safer. World Health Organization, Geneva. 2004: pp 106107. Accessed 10 Apr 2015. doi: doi.org/10.1093/bmb/ldg009

13. Punwasi W. Causes of death in Suriname 2010-2011. Report Bureau Openbare Gezondheidsdienst. Published 2012. Accessed 2 Apr 2015.

14. Verbal Autopsy standards: ascertaining and attributing causes of death. World Health Organization, Geneva 2014: pp 35-97. http://www.who.int/ healthinfo/statistics/verbalautopsystandards/en/ Accessed 28 Mar 2015.

15. De Brouwere V, Zinnen V, Delvaux T, Leke R. Guidelines and tools for organizing and conducting maternal death reviews. Int I Gynaecol Obstet. 2014;127:S21-3.

16. McCaw-Binns A, Lindo J, Lewis-Bell K, Ashley D. Maternal mortality surveillance in Jamaica. Int J Gynaecol Obstet. 2008;100(1):31-6.

17. Ramos S, Karolinski A, Romero M, Mercer R. A comprehensive assessment of maternal deaths in Argentina: translating multicentre collaborative research into action. Bull World Health Organ. 2007;85(8):615-22.

18. Hogan MC, Saavedra-Avendano B, Darney BG, et al. Reclassifying causes of obstetric death in Mexico: a repeated cross-sectional study. Bull World Health Organ. 2016;94(5):362-369B. doi:10.2471/BLT.15.163360

19. Ahmed A, Narcice C, et al. Maternal Mortality, Abortion and Health Sector Reform in four Caribbean Countries: Barbados, Jamaica, Suriname and Trinidad \& Tobago. Overview of Regional Research Findings and Recommendations. Dawn Sexual And Reproductive Health and Rights Program, Caribbean. 2004. http://www.dawnnet.org/feminist-resources/ content/maternal-mortality-abortion-and-health-sector-reform-fourcaribbean-countries-barbados Accessed 22 Oct 2015

20. Horon I. Underreporting of maternal deaths on death certificates and the magnitude of the problem of maternal mortality. Am J Public Health. 2005;95(3):478-82.

21. Horon IL, Cheng D. Effectiveness of pregnancy check boxes on death certificates in identifying pregnancy-associated mortality. Public Health Rep. 2011:126(2):195-200
22. Mgawadere F, Unkels R, van den Broek N. Assigning cause of maternal death: a comparison of findings by a facility-based review team, an expert panel using the new ICD-MM cause classification and a computer-based program (InterVA-4). BJOG. 2016;123(10):1647-53. doi: 10.1111/1471-0528.13969.

23. Alam N, Hobbelink EL, van Tienhoven AJ, van de Ven PM, Jansma EP, Nanayakkara PWB. The impact of the use of the early warning score (EWS) on patient outcomes: a systematic review. Resuscitation. 2014;85(5):587-94.

\section{Submit your next manuscript to BioMed Central and we will help you at every step:}

- We accept pre-submission inquiries

- Our selector tool helps you to find the most relevant journal

- We provide round the clock customer support

- Convenient online submission

- Thorough peer review

- Inclusion in PubMed and all major indexing services

- Maximum visibility for your research

Submit your manuscript at www.biomedcentral.com/submit
Biomed Central 